\title{
PRIMEIROS CASOS AUTÓCTONES DE ESQUISTOSSOMOSE MANSONI EM REGIÂO DO NOROESTE DO ESTADO DE MINAS GERAIS (BRASIL)*
}

\author{
Omar dos Santos Carvalho** \\ Roberto Sena Rocha** \\ Cristiano Lara Massara** \\ Naftale Katz**
}

CARVALHO, O. dos $\mathrm{S}$. et al. Primeiros casos autóctones de esquistossomose mansoni em regiảo do Noroeste do Estado de Minas Gerais (Brasil). Rev. Saúde públ., S. Paulo, 22: 237 - 9, 1988.

RESUMO: Sảo relatados os primeiros casos autóctones de esquistossomose mansoni, originários da cidade de Paracatu, Noroeste do Estado de Minas Gerais, Brasil, região até o momento considerrada indene para esta parasitose. Trata-se de oito pacientes com idade entre 12 e 14 anos, e que nunca haviam se ausentado da localidade. Os levantamentos malacológicos proporcionaram a coleta de 11.471 exemplares de Biomphalaria streminea, todos negativos para Schistosoma mansoni. Foram sugeridas medidas que, se colocadas em prática, poderiam controlar a parasitose na cidade.

UNITERMOS: Esquistossomose mansônica, incidência. Biomphalaria straminea, isolamento

\section{INTRODUÇÃO}

Com a implantação, pela Secretaria de Estado da Saúde, do Programa de Controle da Esquistossomose no Estado de Minas Gerais, a doença foi incorporada ao sistema de notificaçăo compulsória e, em conseqüência, maior número de casos da parasitose tem sido relatado em áreas de baixa endemicidade, bem como em regioes onde nunca havia sido verificada sua ocorrência $4,7,8,11$. Recentemente foi feita notificação, pelo Centro Regional de Saúde de Patos de Minas, à Assessoria Técnica de Saúde, de oito casos de esquistossomose mansoni, diagnosticados nos diversos serviços médicos da cidade de Paracatu.

A cidade de Paracatu, localizada às margens da rodovia BR 040, no Noroeste do Estado de Minas Gerais, dista 239 e $540 \mathrm{~km}$, respectivamente, de Brasília e Belo Horizonte. O município possui cerca de 80.000 habitantes na área urbana e 30.000 na rural.

O clima do município é do tipo Cwa da classificação de Koppen, com inverno seco e temperatura média anual de $24,5^{\circ} \mathrm{C}$. A estação chuvosa estende-se de outubro a março, com média anual de precipitação pluviométrica variando de 900 a $1350 \mathrm{~mm}$.

As principais atividades econômicas estão voltadas a agricultura e para pecuária. A extração de ouro de aluviăo possui grande importấncia econômica. O município, que faz divisa com o Estado de Goiás, pertence a Zona do Urucuia da qual, até o momento, não havia sido relatado caso autóctone de esquistossomose mansoni.

Em outubro/1986, realizou-se inquérito epidemiológico na localidade, que constou de: (a) exame clínico; (b) entrevista (para estabelecer o provável local da transmissão e a autoctonicidade dos casos); (c) exame de fezes; (d) levantamentos malacológicos (realizados em outubro e novembro/1986 em quatro coleçōes hídricas).

Os exames de fezes foram realizados pelo método de Kato-Katz ${ }^{6}$, nas oito crianças, e em 151 escolares do $1^{\mathbf{Q}}$ grau de dois educandários, adjacentes ao córrego Rasgão, com o qual as crianças relataram contato mais freqüente.

Os moluscos capturados com a ajuda de pinça e conchas metálicas foram devidamente acondicionados e examinados em laboratório sob observação de microscópio estereoscópico, após compressão entre placas de vidro.

\section{RESULTADOS}

As oito crianças reexaminadas relataram discreta sintomatologia, tais como: tontura, cefaléia e dor abdominal, não sendo observada a ocorrência de hepatoesplenomegalia. Apenas uma

\footnotetext{
* Trabalho parcialmente financiado pelo Conselho Nacional de Desenvolvimento Científico e Tecnológico (Processo 40.0740/85 PIDE IV).

* Centro de Pesquisas René Rachou/FIOCRUZ - Caixa Postal 1.743 - 30190 - Belo Horizonte, MG - Brasil.
} 
criança, não tratada, anteriormente, continuava parasitada por Schistosoma mansoni, eliminando 468 ovos/g de fezes. Constatou-se, ademais, que elas nunca haviam se ausentado da cidade.

Os exames de fezes realizados nos dois educandários revelaram uma criança $(0,7 \%)$ parasitada por S. mansoni, com um total de 108 ovos/g de fezes.

Os levantamentos malacológicos proporcionaram a captura de 11.471 exemplares de Biomphalaria straminea, todos negativos para cercárias e/ ou esporocistos de $S$. mansoni. Do total de moluscos capturados, $99,2 \%$ foram provenientes do Córrego Rasgăo. Năo foi observada a presença de nenhuma outra espécie de Biomphalaria na área.

\section{COMENTÁRIOS}

Pelos dados obtidos, pode-se afirmar que está ocorrendo transmissão ativa do $S$. mansoni na cidade de Paracatu, resultando no primeiro relato de esquistossomose mansoni autóctone no Noroeste do Estado.

A expansão da esquistossomose mansoni no Estado de Minas Gerais, ou mesmo em outras regiớes do país, tem sido facilitada pelo deslocamento humano, à procura de melhores fontes de trabalho ${ }^{1}$. Na maioria das vezes, nåo encontrando condiçőes sanitárias adequadas, migrantes portadores de $S$. mansoni poluem coleçőes hídricas povoadas por moluscos hospedeiros intermediários do S. mansoni, podendo, desta forma, estabelecer novos focos da doença.

Em Minas Gerais, o foco de Itajubá, no sul do Estado, é, provavelmente, o exemplo mais recente deste mecanismo de expansāo da esquistossomose mansoni, cuja introduçăo teria ocorrido após a criação e desenvolvimento do parque industrial do município ${ }^{235}$.

Em relação a Paracatu, chama a atençăo para o número de pessoas, migrantes do próprio Estado, ou de outras regióes do país, que para ali tem se dirigido, atraídos pela intensa atividade de extração de ouro de aluvião.

A existência, na localidade, de uma população de $B$. straminea 9,10 , associada às precárias condiçōes sanitárias nas quais vivem os migrantes, muitas vezes parasitados pelo $S$. mansoni adaptado à cepa local daquele molusco, foram os fatores que, provavelmente, favoreceram a introdução da doença naquele município.

Por outro lado, o córrego Rasgão, que percorre a céu aberto parte do centro da cidade, recebendo despejos das residências adjacentes às suas margens e densamente povoado por $B$. straminea, tem sido utilizado, com freqüência, por crianças, para a captura de "peixes de aquário" e "gia".

Entretanto, acredita-se que se forem tomadas algumas medidas, o controle da parasitose, na fase em que se encontra, poderá ser conseguido.

Assim sendo, foi sugerido o seguinte elenco de medidas:

1. Realização rotineira de exame de fezes nos principais grupamentos humanos da cidade, tais como escolas, indústrias entre outros, dando-se especial atenção aos migrantes.

2. Tratamento imediato de todos os indivíduos positivos para $S$. mansoni, e controle de cura, através de exame de fezes repetidos, 6 e 12 meses após a medicação.

3. Aplicação temporária, e a curto prazo, de moluscicida, até o término dos exames de fezes e tratamento.

4. Como medida ideal foi sugerida a canalização do córrego Rasgão, face a quantidade de despejos domésticos que recebe, não só para prevenir a transmissão da esquistossomose como também de outras doenças de veiculaçăo hídrica, a que estão expostas as populaçoes localizadas às suas margens.

\section{AGRADECIMENTOS}

Aos Drs. Edson Perini, Elmo A. Caldas e Antonio Lucas R. Correa, da Secretaria da Saúde do Estado de Minas Gerais, e aos funcionários do Centro de Saúde de Paracatu, bem como aos senhores José Geraldo Amorim da Silva e Antonio Carlos do Prado, funcionários do Centro de Pesquisas René Rachou, pela assistência técnica. Ao Dr. W. Lobato Paraense do Depto. de Malacologia (IOC/ FIOCRUZ) pela identificaçặo dos moluscos.

CARVALHO, O. dos S. et. al. [Report on the first authochtonous cases of schistosomiasis mansoni in the Northwest Region of Minas Gerais State (Brazil)]. Rev. Saúde públ., S. Paulo, 22: 237 - 9, 1988.

ABSTRACT: The finding of authochtonous cases of schistosomiasis mansoni at Paracatu, Northwest of Minas Gerais State (Brazil) was reported. They were children of ages ranging from 12 to 14, who had never been out of this town. A total of 11,471 Biomphalaria streminea were collected, and all of them were negative to Schistosoma mansoni cercarias and/or sporocystes. The local authorities were advised on, measures to be taken with a view to schistosomiasis control.

UNITERMS: Schistosomiasis mansoni, occurrence. Biomphalaria straminer, isolation 


\section{REFERÊNCIAS BIBLIOGRÁFICAS}

1. BARRETO, M. P. Movimentos migratórios e sus importância na epidemiologia de doenças parasitárias no Brasil. Rev. Soc. bres. Med. trop., 1: 91-102, 1967.

2. CARVALHO, O. dos S.; KATZ, N.; NAHAS, M. I.; SANTOS, A. R.; NETO JUNIOR, A. P.; FONSECA, M. A. C.; GERALDI, P. Introdução recente da esquistossomose mansoni no sul de Minas Gerais. Itajubá Estudo de caso. [A presentado ao $17^{\circ}$ Congresso da Sociedade Brasileira de Medicina Tropical, Caldas Novas, GO, 1981]

3. CARVALHO, O. dos S.; SOUZA, C. P.; KATZ, N. Primeiro encontro de Biomphalaria tenagophila (D'Orbigny, 1835) naturalmente infectada, com Schistosoma mansoni, em Itajubá, sul do Estado de Minas Gerais, Brasil. Rev. Saúde públ., S. Paulo, 19: 88-91, 1985.

4. KATZ, N. Controle da esquistossomose no Estado de Minas Gerais. In: Reis, F. A.; Faria, I. I.; Katz, N. Mo dernos conhecimentos sobre esquistossomose mansônica. Belo Horizonte, Academia Mineira de Medicina, 1986. p. 51-66. [Suplemento dos Anais da Academia Mineira de Medicina, 1983/1984].

5. KATZ, N. \& CARVALHO, O. dos S. Introdução recente da esquistossomose mansoni no sul do Estado de Minas Gerais, Brasil. Mem. Inst. Oswaldo Cruz, 78: 281-4, 1983.

6. KATZ, N.; CHAVES, A.; PELLEGRNO, J. A simple device for quantitative stool thick-smear technique in schistosomiasis mansoni. Rev. Inst. Med. trop. S. Paulo, 14: 397-400, 1972.

7. KATZ, N.; MOTTA, E.; OLIVEIRA, V. B.; CARVALHO, E. F. Prevalência da esquistossomose em escolares no Estado de Minas Gerais. In: Congresso da Sociedade Brasileira de Medicina Tropical, 148, Joto Pessoa, 1978. Resunos dos temas livres. João Pessoa, 1978. p. 102.

8. LAMBERTUCCI, J. R.; ROCHA, R. S.; CARVALHO, O. dos S.; KATZ, N. A esquistossomose mansoni em Minas Gerais. Rev. Soc. bras. Med. trop., 20: 47-52, 1987.

9. PARAENSE, W. L. Distribuição dos caramujos no Brasil. In: Reis, F. A.; Faria, J.; Katz, N. Modernos conhecimentos sobre esquistossomose mansónica. Belo Horizonte, Academia Mineira de Medicina, 1986. [Suplemento dos Anais da Academia Mineira de Medicina. 1983/1984].

10. PARAENSE, W. L. Fauna planorbídica do Brasil. In: Lacaz, C. S.; Baruzzi, G.R.; Siqueira, J.R., eds. Introduçáo d geografia médica do Brasil. São Paulo., Ed. Edgard Blucher/EdUSP, 1972. p. 213-39.

11. PELLON, A. B. \& TEDXEIRA, L. Distribuiçdo geografica da esquistossomose mansoni no Brasil. Rio de Janeiro, Ministério da Saúde. Divisão de Organização Sanitária, 1950.

Recebido para publicaçăo em 10/7/1987 Reapresentado em 30/12/1987 Aprovado para publicaçäo em 8/1/1988 